\title{
Jan Fabre e a construção de um teatro híbrido
}

\author{
Joana Dória de Almeida
}

O drama do final do século XIX nega em seu conteúdo o que, por fidelidade à tradição, quer continuar a enunciar formalmente (Peter Szondi).

$\mathrm{m}$ resposta à crise do drama tradicional, cujos moldes foram estabelecidos, segundo Szondi, no Renascimento, o século XX é marcado pela experimentação formal e ruptura do modelo dramático clássico. A partir dos anos setenta, grande parte da discussão prática e teórica sobre teatro concentrase nas experiências do que Lehmann define como teatro pós-dramático. ${ }^{1}$ Independente do nome que lhe for atribuído, esse período da história do teatro é caracterizado pela radicalização da pesquisa formal, pela influência profunda de outras linguagens artísticas e pela convivência de experimentações cênicas muito diversas que, por meio da ruptura ou da ênfase em elementos específicos, dialogam com a noção de teatro tradicional, ainda sustentada pelo mercado e associada, no senso comum, à definição desta linguagem artística. ${ }^{2}$

Com a explosão da estrutura do teatro convencional, a cena alternativa contemporânea passou a ser ocupada por grupos e encenadores, como Robert Wilson, Pina Bausch e Romeo Castellucci, entre muitos outros exemplos, cujas criações cênicas mobilizam diversas linguagens artísticas e não se restringem à encenação de um texto dramático preexistente. Os processos criativos desses artistas partem de outras matérias, como o corpo dos atores, o universo de um pintor, as possibilidades de utilização do espaço e a relação com o espectador, para a constituição da linguagem de cada espetáculo.

Joana Dória de Almeida é aluna de graduação do Departamento de Artes Cênicas da ECA-USP.

1 Conceito polêmico por abranger experimentaçôes artísticas muito diversas, mas que, segundo Lehmann, pretende ser "um mínimo denominador comum entre uma série de formas dramáticas muito diferenciadas, mas que têm em comum uma única coisa que é terem atrás de si uma história, que é o teatro dramático" (Lehmann, 2007). Nesse sentido, o termo nos parece apropriado para contextualizar a discussão, muito mais específica, pretendida por este ensaio.

2 Para Lehmann, o teatro sempre se estruturou a partir de três elementos: espaço, tempo e pessoas. Diferente do teatro dramático tradicional, no pós-dramático esses elementos se tornaram independentes uns dos outros e são explorados em cena de maneiras muito variadas (cf. Lehmann, 2007). 
O artista belga Jan Fabre faz parte deste grupo de criadores que expandem a noção de teatro e concentram-se no potencial cênico, naquilo que o teatro desenvolve fora da relação com a literatura dramática. Fabre fez suas primeiras experimentaçôes no campo da performance no final dos anos setenta e, desde então, transitou por várias formas de arte, como a dança, a ópera, o teatro e as artes plásticas. Em 1986, funda o grupo de experimentação cênica Troubleyn, no qual exerce as funçōes de encenador, coreógrafo, dramaturgo e cenógrafo. Além da criação de espetáculos com o Troubleyn, Fabre segue atuando como artista plástico. ${ }^{3}$

O trânsito intenso e contínuo entre as diversas artes resultou numa contaminação entre linguagens e na criação de um trabalho sem fronteiras, marcado pela miscigenação. $\mathrm{O}$ crítico Van Der Dries observa que tal contágio é decorrente, além da múltipla formação artística de Fabre, de seu grande interesse pelo corpo e suas metamorfoses (cf. Dries, 2006). Este é o ponto de partida para qualquer investigação sobre o artista e aquilo que o estimula a promover relações intensas entre as diversas linguagens que utilizam o corpo como elemento fundamental de sua constituição. No processo de criação dos espetáculos, procedimentos de dança, performance, teatro e artes plásticas encontramse e se transformam mutuamente.

Fabre relaciona essas formas artísticas dentro de um projeto de investigação que, em sua maior parte, mobiliza temas e ambiçōes criativas que vão muito além da mera experimentação de linguagens. $\mathrm{Na}$ fase de levantamento e improvisação de materiais para a construção do espetáculo, Fabre reorganiza os elementos característicos de cada uma das linguagens a partir das questões norteadoras do projeto e, propositalmente ou não, os re-contextualiza, gerando um processo de hibridização. A pesquisadora Lúcia Romano esclarece o procedimento:

\begin{abstract}
"Sua operação [da hibridização], diferentemente da justaposição e da complementação, não é de interação entre formas artísticas, mas de transformação daquilo que cada arte conhece de si. (...) os elementos originários não podem sobreviver sem se modificarem, porque as alterações ocorrem na estrutura dos processos de codificação" (Romano, 2005, p. 41).
\end{abstract}

Ao diferenciar a hibridização dos processos de interação e diálogo, aos quais recorriam artistas do princípio do século XX, como V. Meyerhold, A. Artaud, J. Grotowski e E. Piscator, por exemplo, Lúcia Romano define mais precisamente o contexto contemporâneo no que diz respeito às relações entre as linguagens artísticas.

Analisando as experiências de Fabre a partir da ótica da hibridização, percebe-se que, no conjunto final do espetáculo, não interessa se o uso da repetição, por exemplo, surgiu em um ensaio de dança ou foi utilizado em uma performance. A fricção entre as diferentes formas artísticas parece constituir uma outra linguagem cênica, alcançando uma teatralidade característica dos espetáculos contemporâneos. A prática artística de Fabre, que considera o teatro limitado enquanto forma específica, é expandida pelo profundo contato com outras linguagens. Seu teatro é um híbrido de dança, performance e plasticidade, e enfatiza tudo o que pode desenvolver a potencialidade do corpo como expressão.

O principal ponto de partida para a observação do teatro híbrido de Jan Fabre são as relaçôes mantidas entre seus experimentos cênicos e os princípios da arte da performance. É nesta linguagem que o encenador se inicia artisticamente e é a partir dessa experiência que chega à arte teatral. Quando destrói os códigos do teatro que Lehmann define como dramáti-

3 Dados biográficos obtidos no site <www.troubleyn.be>, consultado em 17/10/2007. 
co, o faz principalmente a partir de recursos emprestados da performance.

Segundo Renato Cohen, pode-se considerar a performance uma linguagem antiteatral, na medida em que procura escapar da vertente dominante no teatro, que se apóia no texto dramático, no tempo-espaço ilusionista e numa forma de atuação em que prepondera a interpretação de personagens (Cohen, 2004, p. 56).

Para Adri de Brabandere, entre 1980 e 1984, é Jan Fabre quem introduz a arte da performance no teatro (Brabandere, 1998. p. 11). Provavelmente as características mais fortes resultantes deste processo, e que se tornaram estruturais no teatro do artista são, além da coexistência de diversas formas de arte, a relação direta com a realidade. Diferentemente do teatro dramático, em que nos deparamos com uma dramaturgia que potencializa o recorte ficcional, elegendo e organizando uma série de acontecimentos decisivos, Fabre opta por dilatar o tempo, prolongando a duração de cada movimento ou repetindo-o inúmeras vezes.

Fazendo com que seus atores e bailarinos repitam uma ação inúmeras vezes, Fabre os exaure. Por melhor que seja tecnicamente, qualquer ser humano fatigado é incapaz de repetir uma ação de forma exatamente igual à anterior. O cansaço e a incapacidade do ator, que aparecem em cena de modo evidente, são dados concretos difíceis de ignorar ou de serem aceitos como ficção (Brabandere, 1998).

Além da repetição, Fabre cria uma série de desafios reais, com que os atores têm que lidar concretamente em todas as apresentaçóes. O espetáculo Quando L'uomo Principale e Una Donna, em que a atriz dança em um palco coberto de azeite, é um dos exemplos. Apesar dos ensaios e do desenvolvimento de uma partitura do espetáculo, Fabre constrói uma estrutura de cena mais interessada no imprevisto, usado como dado de realidade e de quebra da convenção, e pouco comum no teatro convencional. Também a noção de personagem é mais aberta no teatro de Fabre, pois não comporta psicologismo e nega a construção de uma realidade ficcional. $\mathrm{O}$ que o artista apresenta em cena não é realismo, mas a tensão entre a realidade do público e dos atores e o universo de símbolos e imagens que consegue projetar (Dries, 2006). $\mathrm{O}$ intuito não é dar forma a uma personagem coerente e verossímil, mas trabalhar com diferentes intensidades energéticas e com o corpo como uma forma em transformação.

$\mathrm{O}$ interesse pelas possibilidades de transformação do corpo explica a fixação de Fabre pelo processo de metamorfose. Talvez por isso, ao analisar a experiência do artista, Hans-Thies Lehmann argumente que, enquanto no teatro dramático interessa a relação entre dois corpos, no teatro pós-dramático de Fabre interessa o que acontece no próprio corpo, que está em permanente conflito entre a pulsão de vida e morte, entre a matéria fluida (sangue, pele, água, etc.) e a matéria estática (esqueleto), que se expandem do corpo do ator para contaminar as próprias formas artísticas (Lehmann, "Prefácio", in Dries, 2006).

Em meio às diversas experiências que povoam a cena contemporânea, Jan Fabre tornouse uma referência importante, especialmente por expandir os limites das linguagens artísticas sobre as quais se debruçou. Seu teatro híbrido aponta um caminho, reafirmado por outras experiências, no qual cada vez existirão menos fronteiras entre as linguagens artísticas. 


\section{Referências bibliográficas}

BRABANDERE, Adri de. Performing arts portraits. Jan Fabre. Brussels: Vlaams Theater Instituut, 1998.

COHEN, Renato. Performance como linguagem. São Paulo: Perspectiva, 2004.

DRIES, Luk Van den. Corpus Jan Fabre. Observations of a creative process. Burggravenlann: Imschoot Uitgevers, 2006.

FABRE, Jan. The power of theatrical madness. London: ICA, 1984.

LEHMANN, Hans-Thies. Postdramatic theatre. London: Routledge, 2006.

O teatro pós-dramático. São Paulo: Cosac \& Naify, 2007.

ROMANO, Lúcia. O teatro do corpo manifesto: teatro físico. São Paulo: Perspectiva/Fapesp, 2005.

SZONDI, Peter. Teoria do drama moderno (1880-1950). São Paulo: Cosac \& Naify, 2001. 